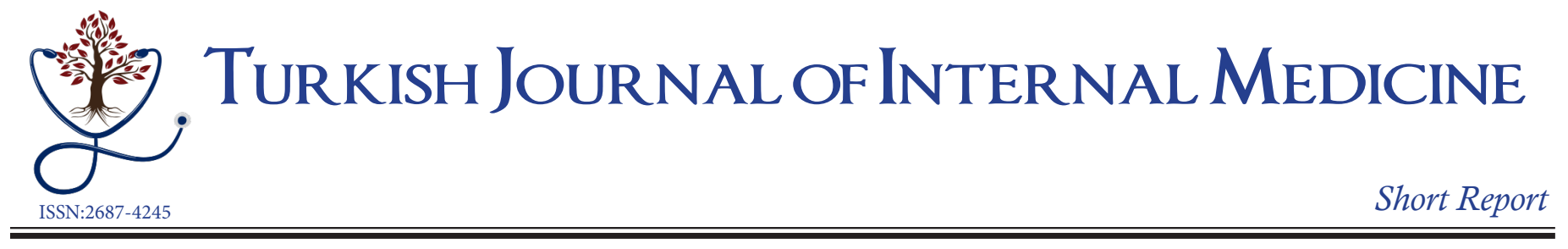

\title{
The comparison of obese and non-obese persons in terms of food addiction
}

\author{
Hacer Hicran MUTLU ${ }^{1}$, Hasan Hüseyin MUTLU² \\ ${ }^{1}$ Istanbul Medeniyet University Faculty of Medicine, Department of Family Medicine, Istanbul, Turkey \\ ${ }^{2}$ Istanbul Medeniyet University Faculty of Medicine, Department of Medical Education, Istanbul, Turkey
}

Turk J Int Med 2021;3(Supplement 1):S23-S24

DOI: $\underline{10.46310 / \text { tjim. } 875717}$

Keywords: Feeding and Eating Disorder, Addictive Behavior, Obesity

Although the term 'addiction' was previously used only to describe excessive alcohol and substance abuse, it has recently been realized that some behaviors have a neurobiological basis similar to alcohol and substance addiction. Food addiction is one of these behaviors. In many studies, it has been suggested that especially obese and overeating people have food addiction. ${ }^{1,2}$ The aim of our study was to compare the food addiction prevalence among obese and nonobese persons who applied to obesity and family medicine outpatient clinics.

The patients who applied to the Family Medicine outpatient clinic and obesity outpatient clinic between 15.01.2019-30.06.2019 were included in the study. The age, gender, weight, height, and smoking status of the patients were questioned. Yale Food Addiction Scale which was developed by Gearhardt et al. ${ }^{1}$ and adapted to the Turkish language by Bayraktar et $\mathrm{al}^{2}{ }^{2}$ was conducted on the individuals who volunteer to participate in the study.

195 patients without obesity and 403 patients with obesity were included in the study. The mean age and body mass index, the distribution of gender, and smoking status of the individuals were shown in Table 1 . The food addiction prevalence in the obese group was $33.7 \%$ and $14 \%$ in the nonobese group. The prevalence of food addiction was significantly higher in obese individuals $(\mathrm{p}<0.001$, OR: 3.13, 95\% Cl: 2.09-4.68).

The prevalence of food addiction varies between $1.60 \%$ and $24 \%$ in non-obese people and $7.7 \%$ and $56.8 \%$ in obese people in different populations. ${ }^{1,3-7}$ Food addiction prevalence among obese and non-obese people detected in our study was in harmony with the literature. In a study comparing food addiction prevalence in obese and non-obese individuals, food addiction was more common among obese persons. ${ }^{8}$ Contrarily, food addicted individuals did not differ in body mass index from non-addicted participants in another sample. ${ }^{9}$ Food addiction is a discussed concept recently. Food addiction should be considered as a behavioral addiction and should be treated as an addiction. It is detected more common in obese

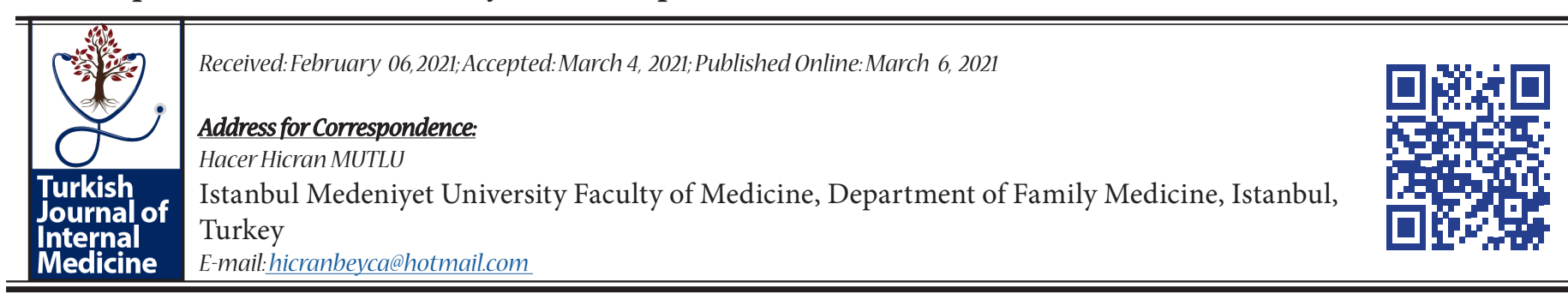


Table 1. Comparison of sociodemographic features of obese and non-obese individuals

\begin{tabular}{lcc}
\hline Variables & $\begin{array}{c}\text { Non-obese Group } \\
\mathbf{n = 4 0 3}\end{array}$ & $\begin{array}{c}\text { Obese Group } \\
\mathbf{n = 1 9 5}\end{array}$ \\
\hline Age (years) & $22.44 \pm 7.5$ & $45.01 \pm 13.09$ \\
Gender & & \\
Female (n, \%) & $264(61.4)$ & $166(38.6)$ \\
Male (n, \%) & $179(86.1)$ & $29(13.9)$ \\
BMI (kg/m $\left.{ }^{2}\right)$ & $22.49 \pm 2.8$ & $35.56 \pm 4.6$ \\
Smoking & & \\
Yes (n, \%) & $40(9)$ & $36(47.4)$ \\
No (n, \%) & $403(91)$ & $159(28.2)$ \\
\hline
\end{tabular}

mean \pm SD.

individuals than in those who are non-obese. Therefore, food addiction should be screened and treated in obese individuals.

\section{Conflict of Interests}

Authors declare that there are none.

\section{Acknowledgment}

This study has been presented in $17^{\text {th }}$ Uludag Internal Medicine National Winter Congress, $6^{\text {th }}$ Bursa Family Medicine Association National Congress, $11^{\text {th }}$ Uludag Internal Medicine Nursing Congress, 5-7 March 2021, Bursa, Turkey.

\section{References}

1. Gearhardt AN, Corbin WR, Brownell KD. Development of the Yale Food Addiction Scale Version 2.0. Psychol Addict Behav. 2016 Feb;30(1):113-21. doi: 10.1037/adb0000136.

2. Bayraktar F, Erkman F, Kurtulus E. Adaptation study of Yale food addiction Scale. Klin Psikofarmakol Bul. 2012;22(1):S38.

3. Karlsson HK, Tuominen L, Tuulari JJ, Hirvonen
J, Parkkola R, Helin S, Salminen P, Nuutila P, Nummenmaa L. Obesity is associated with decreased $\mu$-opioid butunaltered dopamine D2 receptoravailability in the brain. J Neurosci. 2015 Mar 4;35(9):3959-65. doi: 10.1523/JNEUROSCI.4744-14.2015.

4. Kafes AY, Ülker S, Sayar GH. Yeme ba $\square 1 \mathrm{ml} 111 \square 1$. Current Addiction Research 2018;2(2):54-8 (in Turkish). doi: 10.5455/car.105-1537591260.

5. Oyekcin DG, Deveci A. Etiology of food addiction. Current Approaches in Psychiatry. 2012 June;4(2):13853 (in Turkish). doi: 10.5455/cap.20120409.

6. Leigh SJ, Morris MJ. The role of reward circuitry and food addiction in the obesity epidemic: An update. Biol Psychol. 2018 Jan;131:31-42. doi: 10.1016/j. biopsycho.2016.12.013.

7. Brunault P, Ducluzeau PH, Courtois R, BourbaoTournois C, Delbachian I, Réveillère C, Ballon N. Food addiction is associated with higher neuroticism, lower conscientiousness, higher impulsivity, but lower extraversion in obese patient candidates for bariatric surgery. Subst Use Misuse. 2018 Sep 19;53(11):19191923. doi: 10.1080/10826084.2018.1433212.

8. Meule A, Vogele C, Kübler A. German translation and validation of the Yale Food Addiction Scale. Diagnostica 2012;58:115-26. doi: 10.1026/0012-1924/ a000047.

9. Meule A. Food addiction and body-mass-index: a non-linear relationship. Med Hypotheses. 2012 Oct;79(4):508-11. doi: 10.1016/j.mehy.2012.07.005. 